\title{
DESENVOLVIMENTO DE MUDAS DE MARACUJAZEIRO 'BRS RUBI DO CERRADO’ COM A UTILIZAÇÃO DE ÁCIDO GIBERÉLICO
}

\author{
Rafael Augusto Ferraz ${ }^{1 *}$, Bruno Henrique Leite Gonçalves ${ }^{1}$, Jackson Mirellys Azevêdo \\ Souza $^{1}$, Marco Antonio Tecchio ${ }^{2}$
}

\footnotetext{
1 Doutorando em Agronomia, Departamento de Horticultura, Universidade Estadual Paulista 'Júlio de Mesquita Filho' - UNESP, Botucatu - SP, Brasil.*Email: rafaelferraz86@ hotmail.com

2 Docente do Departamento de Horticultura, Universidade Estadual Paulista 'Júlio de Mesquita Filho' UNESP, Botucatu - SP, Brasil.
}

RESUMO: Foram avaliados os efeitos do ácido giberélico no desenvolvimento das mudas de maracujazeiro 'BRS Rubi do Cerrado' (híbrido de maracujazeiro-azedo ou amarelo: Passiflora edulis f. flavicarpa). Os tratamentos consistiram em seis doses de ácido giberélico $\left(\mathrm{AG}_{3}\right)$ : 0, 30, 60, 90, 120 e $150 \mathrm{mg} \mathrm{L}^{-1}$, aplicadas via pulverização foliar. Foram realizadas quatro pulverizações foliares com $\mathrm{AG}_{3}$ aos $0,15,30$ e 45 dias após o transplantio das mudas para as sacolas plásticas. Realizaram-se as avaliações aos 0, 15, 30, 45 e 60 dias após o transplantio. As variáveis avaliadas foram: número de folhas; massa seca da parte aérea, caule e raiz; comprimento da raiz; diâmetro e comprimento do caule; índice de área foliar e índice SPAD. Houve efeito isolado das doses de $\mathrm{AG}_{3}$ e das épocas de avaliação para a maioria das variáveis avaliadas. Obtiveram-se nas mudas do maracujazeiro cultivar BRS Rubi do Cerrado melhores resultados utilizando-se $150 \mathrm{mg} \mathrm{L}^{-1}$ com maior desenvolvimento aos 60 dias após o transplantio.

Palavras-chave: Passiflora edulis f. flavicarpa. Pulverização foliar.

\section{DEVELOPMENT OF PASSION FRUIT SEEDLINGS 'BRS RUBI DO CERRADO’ WITH THE USE OF GIBBERELLIC ACID}

\begin{abstract}
Were evaluated the effects of gibberellic acid in the development of passion fruit 'BRS Rubi do Cerrado' seedlings (hybrid passion fruit or yellow: Passiflora edulis f. flavicarpa). The treatments consisted of six concentration of gibberellic acid $\left(\mathrm{GA}_{3}\right), 0,30$, 60, 90, 120 and $150 \mathrm{mg} . \mathrm{L}^{-1}$, applied foliar pulverization. Four foliar pulverizations were performed with $\mathrm{GA}_{3}$, the $0,15,30$ and 45 days after transplanting of seedlings to plastic bags. Evaluated at 0, 15, 30, 45 and 60 days after transplanting. The variables evaluated were: number of leaves; dry eight of shoots, stem and root; root length; diameter and stem length; leaf area índex and SPAD índex. There were isolated effect of $\mathrm{GA}_{3}$ concentrations and evaluation times for the majority of variables. Obtained in passion fruit 'BRS Rubi do Cerrado' seedling better results using $150 \mathrm{mg} \mathrm{L}^{-1}$, with further development at 60 days after transplanting.
\end{abstract}

Key words: Passiflora edulis f. flavicarpa. Foliar pulverization.

Cultura Agronômica, Ilha Solteira, v.25, n.2, p.167-174, 2016 


\section{INTRODUÇÃO}

O maracujazeiro é uma frutífera da família Passifloracea, gênero Passiflora, bastante cultivada e explorada de norte a sul do território brasileiro e de bom retorno econômico. É uma planta de clima tropical com ampla distribuição geográfica, sendo o Brasil o principal produtor mundial.

A cultura do maracujá está em franca expansão tanto para a produção de frutas para o consumo "in natura" como para a produção de suco. Segundo Leonel e Pedroso (2005), o maracujazeiro pode ser propagado por sementes, estaquia, mergulhia ou enxertia, embora a multiplicação por sementes seja mais usual para o estabelecimento de plantações comerciais de maracujá, visando a facilidade de realização e o menor custo de produção das mudas, considerando-se principalmente a longevidade da cultura, que tem sido diminuída em função de problemas fitossanitários. A produção de mudas constitui-se em uma das etapas mais importantes do sistema produtivo, uma vez que a produção de frutos de qualidade e a produtividade dependem do uso de boa técnica para formação das mudas e tal fator responde por $60 \%$ do sucesso de implantação e estabelecimento da cultura (ZACCHEO et al., 2013).

Diferentes práticas podem ser utilizadas quanto à produção de mudas de qualidade. $\mathrm{O}$ uso de reguladores vegetais, por exemplo, já é uma prática comum em vários países (TECCHIO et al., 2015). De acordo com os mesmos autores o ácido giberélico tem sido o produto mais utilizado no processo de produção e formação de mudas frutíferas.

Os reguladores vegetais influenciam a resposta de vários órgãos da planta e esses estão envolvidos no crescimento e desenvolvimento de um órgão ou tecido vegetal, podendo estes processos serem alterados de acordo com as condições fisiológicas da planta. No caso do ácido giberélico em específico, seu uso promove maior elongação e divisão celular, que ocorre devido o aumento no comprimento e no número de células (TAIZ; ZEIGER, 2008).

Em experimentos com o maracujazeiro amarelo e o doce, Santos et al. (2010) e Leonel e Pedroso (2005), respectivamente, ao utilizarem $\mathrm{AG}_{3}$ via pulverização foliar, verificaram aumento significativo da parte aérea das plantas.

Diante do exposto, o presente trabalho objetivou avaliar o uso do ácido giberélico no desenvolvimento de mudas de maracujazeiro 'BRS Rubi do Cerrado'.

\section{MATERIAL E MÉTODOS}

O trabalho foi realizado em viveiro telado e no laboratório de Fruticultura do Departamento de Horticultura da Faculdade de Ciências Agronômicas da UNESP em Botucatu-SP, no período de setembro a novembro de 2013.

As sementes do maracujazeiro cv. BRS Rubi do Cerrado (híbrido de maracujazeiroazedo ou amarelo: Passiflora edulis f. flavicarpa) foram adquiridas junto a Embrapa Cerrados. Amostras de 400 sementes foram acondicionadas em papel 'germitest' umedecido e dispostas em câmara de germinação do tipo BOD em temperatura de $25^{\circ} \mathrm{C}$. Após 35 dias, 
quando a maior parte das sementes já havia germinado e formado plântulas normais, realizou-se o transplantio, colocando-se duas plântulas por sacolas de polietileno preto, com capacidade de $500 \mathrm{~g}$, contendo mistura de solo (nitossolo vermelho) e composto orgânico, na proporção 4:1, onde se adicionou para cada 500 litros da mistura, $2 \mathrm{~kg}$ de superfosfato simples, $400 \mathrm{~g}$ de cloreto de potássio e $1 \mathrm{~kg}$ de calcário dolomítico. Após o transplante, as sacolas de polietileno foram levadas para o viveiro telado de $50 \%$ de sombreamento, com irrigação por microaspersão.

Os tratamentos consistiram em seis doses de ácido giberélico $\left(\mathrm{AG}_{3}\right)$ : 0, 30, 60, 90, 120 e $150 \mathrm{mg} \mathrm{L}^{-1}$, aplicadas via pulverização foliar. Foram realizadas quatro pulverizações foliares com $\mathrm{AG}_{3}$, aos $0,15,30$ e 45 dias após o transplantio das mudas para as sacolas plásticas. O produto comercial utilizado foi o Pro-Gibb®, embalado pela Abott Laboratórios do Brasil Ltda, contendo $\mathrm{AG}_{3}$ a 10\%. Realizaram-se as avaliações aos 0, 15, 30, 45 e 60 dias após o transplantio. As variáveis avaliadas foram: número de folhas; massa seca da parte aérea, caule e raiz, expressa em gramas e realizada em balança analítica; comprimento da raiz, em centímetros, aferido com auxílio de régua graduada; diâmetro e comprimento do caule, em milímetros, usando-se paquímetro digital; índice de área foliar, realizada em Área Meter, modelo 3100 LI, e expresso em decímetros quadrados e índice SPAD.

O delineamento experimental utilizado foi o de blocos casualizados com parcelas subdivididas, sendo as parcelas representadas pelas doses de $\mathrm{AG}_{3}$ as subparcelas pelas épocas de avaliações. Os dados obtidos foram submetidos à análise de variância e quando houve efeito significativo, foi realizada a análise de regressão, com o uso do programa computacional Sisvar (FERREIRA, 2011).

\section{RESULTADOS E DISCUSSÃO}

Houve efeito isolado das doses de AG3 e das épocas de avaliação para a maioria das variáveis avaliadas, ajustando-se modelos de regressão com os valores médios obtidos.

Considerando-se as épocas de avaliação do transplante até os 60 dias, houve aumento linear na altura da planta (Figura 1-A), no comprimento das raízes (Figura 1-C), na matéria seca do caule (Figura 1-D), das folhas (Figura 1-E) e das raízes (Figura 1-F), sendo os maiores valores obtidos aos 60 dias após o transplante. Referente ao diâmetro do caule, o modelo de regressão quadrático foi significativo para expressar a variação dos dados, com o ponto de máximo obtido aos 60 dias após o transplantio das mudas (Figura 1-B). Segundo Verdial et al. (2000) o tamanho da muda influencia o desenvolvimento inicial das mesmas, sendo que mudas maiores tendem a formar plantas mais desenvolvidas após o transplante.

Cultura Agronômica, Ilha Solteira, v.25, n.2, p.167-174, 2016 

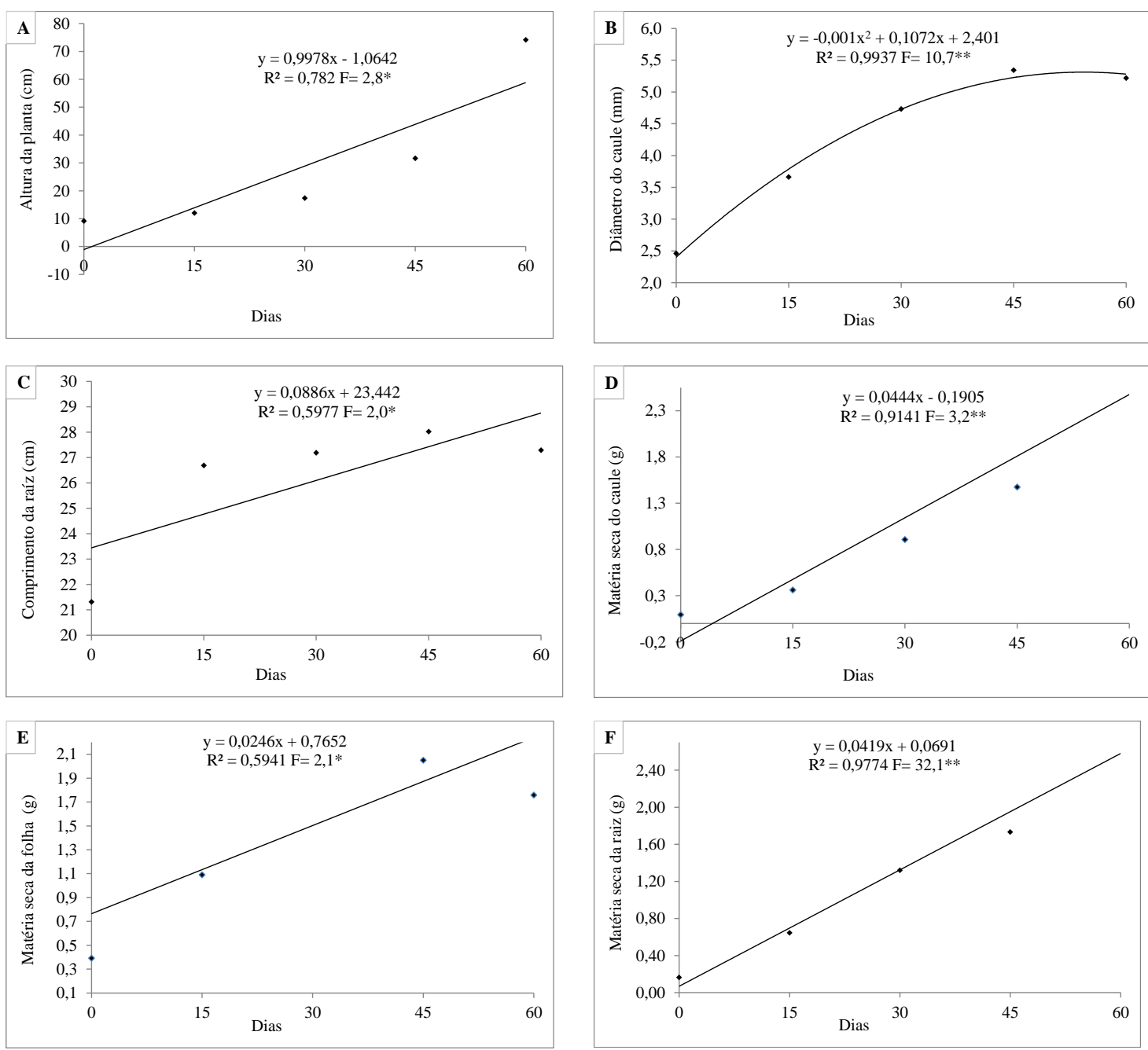

Figura 1. Altura média da planta (A), diâmetro do caule (B), comprimento da raiz (C), matéria seca do caule (D), matéria seca das folhas (E) e da matéria seca das raízes (F) de mudas de maracujazeiro do transplante aos 60 dias. Botucatu-SP, 2013

Referente às doses de ácido giberélico, houve efeito significativo do AG3 no número de folhas (Figura 2-A), e na matéria seca do caule (Figura 2-B) e das folhas (Figura 2-C), ajustando-se modelos de regressão linear. Comparando-se com a dose zero, a dose de 150 $\mathrm{mg} \mathrm{L}^{-1}$ proporcionou um incremento no número de folhas, na matéria seca do caule e das folhas de $20 \%, 14 \%$ e $8 \%$, respectivamente. 

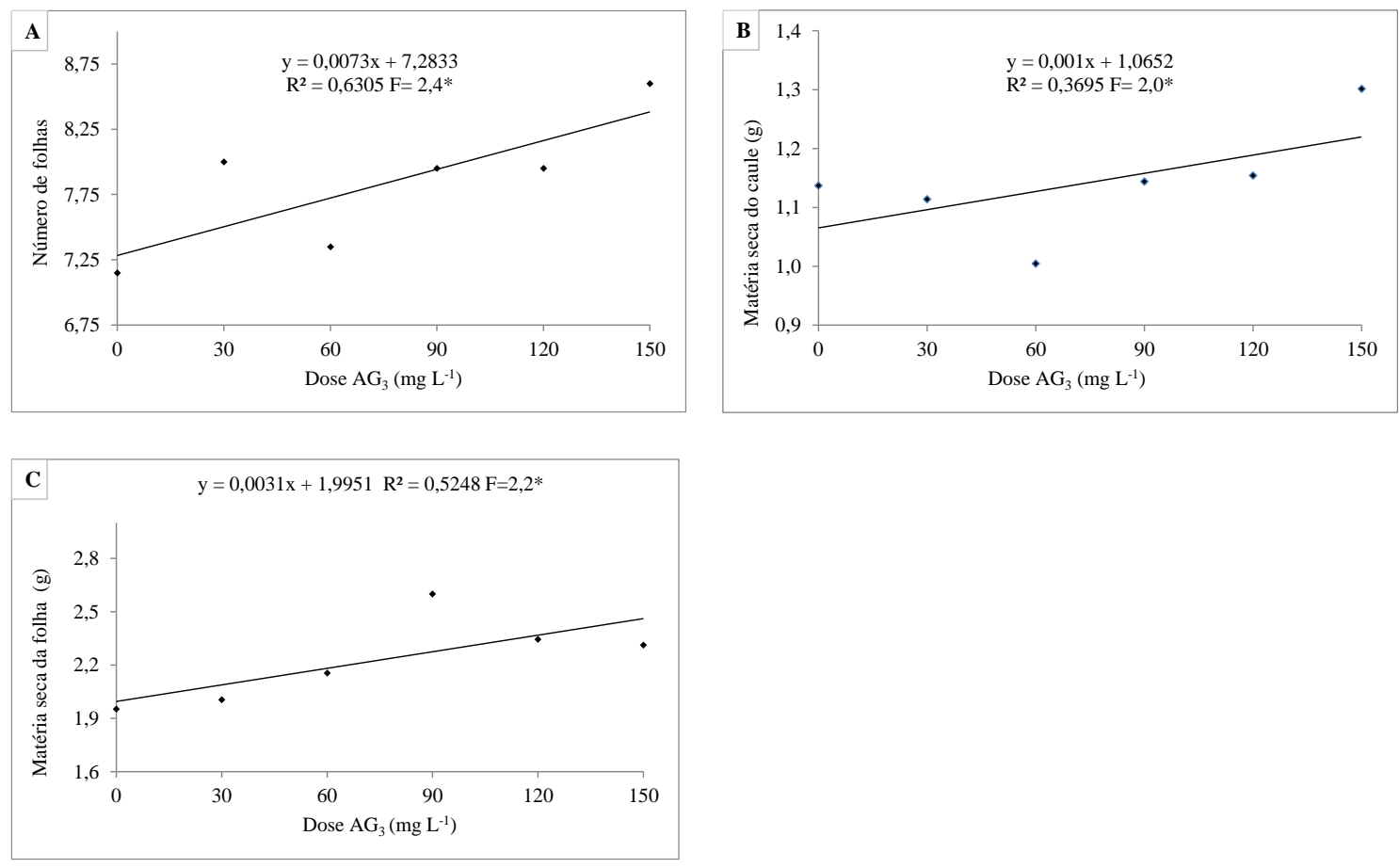

Figura 2. Número médio de folhas (A), matéria seca do caule (B) e das folhas (C) de mudas de maracujazeiro submetidas a doses de ácido giberélico $\left(\mathrm{AG}_{3}\right)$. Botucatu-SP, 2013.

Estes dados corroboram com Santos et al. (2010), que ao utilizaram $\mathrm{AG}_{3}$ nas doses de $0,20,40,80$ e $160 \mathrm{mg} \mathrm{L}^{-1}$, via pulverização foliar, proporcionaram aumentos significativos na massa seca e total em plantas de maracujazeiro, com as doses variando de 78 e $92 \mathrm{mg} \mathrm{L}^{-}$ 1. Ainda segundo os mesmos autores, doses de $\mathrm{AG}_{3}$ entre 90 e $100 \mathrm{mg} \mathrm{L} \mathrm{L}^{-1}$, promoveram crescimento expressivo no comprimento do caule. Leonel e Pedroso (2005), utilizando o $\mathrm{AG}_{3}$, obtiveram aumentos significativos na altura de plantas e no número de folhas, onde os melhores resultados foram obtidos com a dose de $300 \mathrm{mg} \mathrm{L}^{-1}$.

Efeito semelhante foi verificado por Modesto et al. (1994), que ao utilizarem plântulas de limão Cravo (Citrus limonia Osbeck), observaram que o ácido giberélico nas doses de 0 , 25, 50, 100 e $150 \mathrm{mg} \mathrm{L}^{-1}$ em intervalos quinzenas, influenciou no desenvolvimento da parte aérea das plântulas. Scalon et al. (2006), quando pulverizaram giberelina em mudas de orelha-de-macaco (Enterolobium contortisiliqunn (Vell.) Morong), obtiveram incremento da parte aérea de plantas. Incremento significativo no caule, também foi verificado por Wagner Junior et al. (2008), que após realizarem pulverização foliar com $\mathrm{AG}_{3}$ nas doses de 0,50 , 100,150 e $200 \mathrm{mg}$ L obtiveram incremento crescente em plantas de pessegueiro.

Segundo Higashi et al. (2002), as giberelinas são mais frequentemente associadas à promoção de crescimento da parte aérea e a aplicação de giberelinas pode induzir grandes aumentos na altura das plantas. Elas atuam em diversos fenômenos fisiológicos, no entanto, o gênero ou a espécie somado a outros fatores, podem determinar o efeito específico na resposta.

Cultura Agronômica, Ilha Solteira, v.25, n.2, p.167-174, 2016 
A produção de matéria seca pela planta, nos últimos tempos, tem sido utilizada como fator relevante para se avaliar a qualidade de mudas, todavia, há o inconveniente de ser preciso a destruição total da planta para sua mensuração, o que a torna inviável em muitos viveiros (ARRIEL et al., 2006).

Para o índice de área foliar e índice SPAD não houve modelos de regressão significativo para expressar a variação dos dados obtidos. Oliveira et al. (2005) relatam que aplicações de $\mathrm{AG}_{3}$ não foram adequadas para incrementar o diâmetro do caule em maracujazeiro-doce mesmo com 63 dias após a semeadura, do mesmo modo que no trabalho de Braz (2002) com o uso de 25; 50; 75; 100; 200; 300 e 400 mg L ${ }^{-1}$ de $\mathrm{AG}_{3}$ em mudas de Passiflora f. flavicarpa Deg. Os mesmos autores relatam que a $\mathrm{AG}_{3}$ também não foi efetivo para promover o aumento do comprimento do caule, tendo melhores resultados a aplicação de $\mathrm{AG}_{4}$ e $\mathrm{AG}_{7}$ associadas à citocinina fenilmetilaminopurina.

Considerando-se as citações de Taiz e Zeiger (2008) de que $A_{1}$ é a giberelina biologicamente ativa, enquanto $\mathrm{AG}_{3}$ é rara em plantas superiores e $\mathrm{AG}_{4}$ ocorre apenas em algumas espécies e que ambas são tão efetivas quanto $\mathrm{AG}_{1}$ em bioensaios, pode-se relatar que as concentrações de $\mathrm{AG}_{3}$ aplicadas neste experimento foram baixas, não promovendo alongamento significativo.

O comprimento da raiz e massa seca da mesma não diferiram para as diferentes concentrações de $\mathrm{AG}_{3}$, resultados que podem ser explicados pelo fato da giberelina atuar de forma pouco marcante no crescimento da raiz conforme sugeriram Taiz e Zeiger (2008). Segundo Franco et al., (2005) o maior volume de raízes é fundamental para o sucesso das mudas após o transplante no campo, visto que este fator está diretamente ligado com a taxa de sobrevivência das plantas, sendo assim, tornam-se necessários mais estudos para uma combinação mais adequada de reguladores vegetais, os quais possam promover um bom crescimento tanto da parte aérea como da raiz.

\section{CONCLUSÃO}

O uso de ácido giberélico na dose de $150 \mathrm{mg} . \mathrm{L}^{-1}$ pulverizado via foliar, promove melhor desenvolvimento de mudas do maracujazeiro amarelo, cultivar BRS Rubi do Cerrado, com melhores resultados aos 60 dias após o transplantio.

\section{REFERÊNCIAS BIBLIOGRÁFICAS}

ARRIEL, E. F.; PAULA, R. C.; Rodrigues, T. J. D.; BAKKE, O. A.; ARRIEL, N. H. C. Divergência genética entre progênies de Cnidoscolus phyllacanthus submetidas a três regimes hídricos. Científica, Jaboticabal, v. 34, n. 2, p.229-237, 2006.

BRAZ, A. L .M. Crescimento de mudas de maracujazeiro-azedo (Passiflora edulis f. flavicarpa Deg.) tratadas com reguladores vegetais. Marechal Cândido Rondon: Faculdade de Agronomia, Universidade Estadual do Oeste do Paraná, 2002. 48 p. (Monografia), 2002.

Cultura Agronômica, Ilha Solteira, v.25, n.2, p.167-174, 2016 
FERREIRA, D. F. Sisvar: a computer statistical analysis system. Ciência e Agrotecnologia, Lavras, v. 35, n. 6, p.1039-1042, 2011.

FRANCO, C. F.; PRADO, R. M.; BRAGHIROLLI, L. F.; LEAL, R. M.; PEREZ, E. G.; ROMUALDO, L. M. Uso da poda e de diferentes diâmetros de alporques sobre o desenvolvimento e acúmulo de nutrientes de mudas de lichieira. Revista Brasileira de Fruticultura, Jaboticabal, v. 27, n. 3, p.491-494, 2005.

HIGASHI, E. N.; SILVEIRA, R. L. V. A.; GOUVÊA, C. F.; BASSO, L. H. M. Ação fisiológica de hormônios vegetais na condição hídrica, metabolismo e nutrição mineral. In: CASTRO, P. R. C.; SENA, J. O. A.; KLUGE, R. A. (ed.) Introdução à fisiologia do desenvolvimento vegetal. Maringá: Universidade Estadual de Maringá, 2002. p. 175-186.

LEONEL, S.; PEDROSO, C. J. Produção de mudas de maracujazeiro doce com o uso de biorregulador. Revista Brasileira de Fruticultura, Jaboticabal, v. 27, n. 1, p.107-109, 2005.

MODESTO, J. C.; RODRIGUES, J. D.; PINHO, S. Z. Efeitos da aplicação de ácido giberélico $\left(\mathrm{GA}_{3}\right)$ em "seedlings" de limão "Cravo' (Citrus limonia Osbeck). In: 46 ${ }^{\mathrm{a}}$ REUNIÃO ANUAL DA SBPC, 46., 1994, Vitória. Anais... Vitória: Universidade Federal do Espírito Santo, 1994. p. 16.

OLIVEIRA, A.; FERREIRA, G.; RODRIGUES, J. D.; FERRARI, T. B.; KUNZ, V. L.; PRIMO, M. A.; POLETTI, L. D. Efeito de reguladores vegetais no desenvolvimento de mudas de Passiflora alata Curtis. Revista Brasileira de Fruticultura, Jaboticabal, v. 27, n. 1, p. 9-13, 2005.

SANTOS, C. A. C.; VIEIRA, E. L.; PEIXOTO, C. P.; BENJAMIM, D. A.; SANTOS, C. R. S. Crescimento inicial de plantas de maracujazeiro amarelo submetidas à giberelina. Comunicata Scientiae, Bom Jesus, v. 1, n. 1, p.29-34, 2010.

SCALON, S. P. Q.; MUSSURY, R. M.; GOMES, A. A.; SILVA, K. A.; WATHEIR, F.; FILHO, H. S. Germinação e crescimento inicial da muda de orelha-de-macaco (Enterolobium contortisiliqunn (Vell.) Morong): efeitos de tratamentos químicos e luminosidade. Revista Árvore, Viçosa, v. 30, n. 4, p.529-536, 2006.

TAIZ, L.; ZEIGER, E. Fisiologia Vegetal. Porto Alegre: Artmed, 2008. 820 p.

TECCHIO, M. A.; LEONEL, S.; REIS, L. L.; SIMONETTI, L. S.; SILVA, M. J. R. Stimulate no desenvolvimento de mudas de Kunquat 'Nagami'. Irriga, Botucatu, edição especial, p.97-106, 2015.

VERDIAL, M. F.; LIMA, M. S.; TESSARIOLI-NETO, J.; DIAS, C. T. S.; BARBANO, M. T. Métodos de formação de mudas de maracujazeiro amarelo. Scientia Agrícola, Piracicaba, v. 57, n. 4, p.795-798, 2000.

ZACCHEO, P. V. C.; AGUIAR, R. S.; STENZEL, N. M. C.; NEVES, C. S. V. J. Tamanho de recipientes e tempo de formação de mudas no desenvolvimento e produção de maracujazeiro-amarelo. Revista Brasileira de Fruticultura, Jaboticabal, v. 35, n. 2, p.603607, 2013.

Cultura Agronômica, Ilha Solteira, v.25, n.2, p.167-174, 2016 
WAGNer JUNiOR, A.; Silva, J. O. C.; SANTOS, C. E. M.; PIMENTEL, L. D.; NEGREIROS, J. R. S. N.; BRUCKNER, C. H. Ácido giberélico no crescimento inicial de mudas de pessegueiro. Ciência e Agrotecnologia, Lavras, v. 32, n. 4, p.1035-1039, 2008. 